\title{
An overlooked issue in frozen shoulder: Miyofascial trigger point
}

\author{
Donuk omuzda gözden kaçan bir durum: Miyofasyal tetik nokta
}

\section{(D) Fatih BAĞCIER}

To the Editor,

We are thinking that Miyofascial trigger point (MTrP), maybe a part of problem in adhesive capsulitis (AC). Etiology of $A C$ is complex, known risk factors include diabetes mellitus, thyroid diseases, myocardial infarction, dupuytren's contracture, trauma, and autoimmune diseases. ${ }^{[1]}$ Besides, it is thought that MTrP in shoulder muscles may play a role in $\mathrm{AC}^{[2]}$ In the literature, there are studies indicating that treatments for MTrPs detected in the shoulder girdle in patients with AC may have an efficacy on pain and functionality parameters. Jankovic and Van Zundert ${ }^{[3]}$ achieved successful results in the case series in which they administered local anesthetic injection to MTrP in subscapularis muscle and nerve block in the suprascapular nerve. Clewley et al. ${ }^{[4]}$ applied a total of 13 sessions of dry needling treatment to a patient for 6 weeks; targeting MTrPs in the upper trapezius, levator scapulae, deltoid, and infraspinatus muscles, a rapid improvement was observed in the patient. It is thought that the problem in AC is not only about capsule but also accompanied by shortness of muscle, fascia restriction, and MTrPs in muscles. Therefore, while planning treatment, these structures should also be evaluated by physical examination and possible problems should be treated. In addition, due to the complex kinematic structure of the shoulder region, MTrP has been associated not only with AC but also with pathologies such as chronic shoulder pain, shoulder impingement syndrome, and postoperative contracture ${ }^{[5]}$ Here, we do not claim that MTrP is an etiological cause in AC.
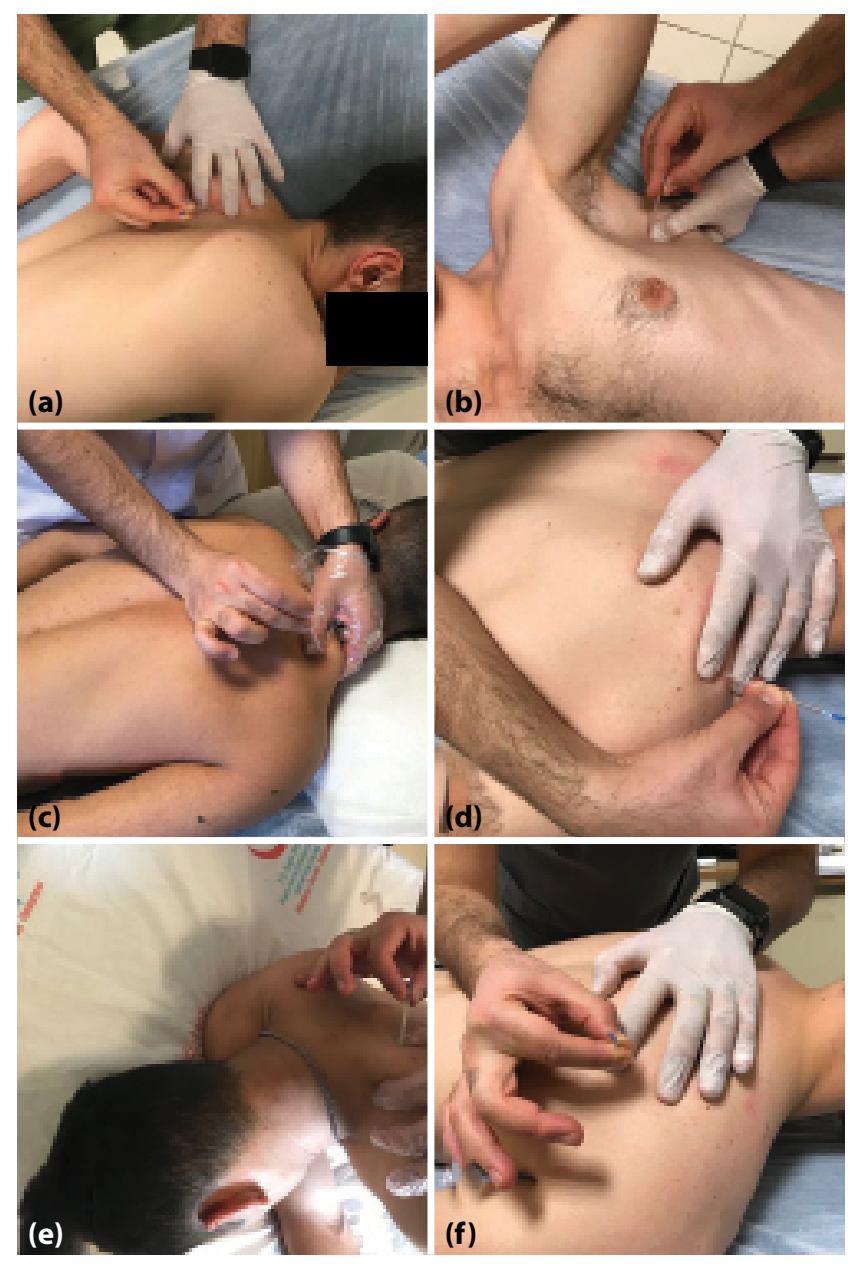

Figure 1. Dry needling treatment of muscles for adhesive capsulitis. (a) Subscapularis medial part. (b) Subscapularis lateral part. (c) Upper trapezius. (d) Lateral deltoid. (e) Levator scapulae. (f) Infraspinatus.

However, we recommend that upper trapezius, subscapularis, levator scapulae, deltoid, and infraspinatus muscles should be examined in detail and treated if MTrP is detected in patients with AC (Fig. 1). MTrP is a

Departmant of Physical Medicine and Rehabilitation, Biruni University Faculty of Medicine, İstanbul, Turkey

Submitted: 31.05.2020 Accepted after revision: 08.07.2020 Available online date: 09.07.2020

Correspondence: Dr. Fatih Bağcıer. Biruni Üniversitesi Tıp Fakültesi Hastanesi, Fiziksel Tıp ve Rehabilitasyon Anabilim Dalı, İstanbul, Turkey.

Phone: +90 - 4448276 e-mail: bagcier_42@hotmail.com

(c) 2021 Turkish Society of Algology 
common but overlooked diagnosis. Sometimes it is primary pathology, sometimes it can accompany primary pathology. It should be remembered that the diagnosis must come to mind before making a diagnosis.

\section{References}

1. Cho $\mathrm{CH}, \mathrm{Bae} \mathrm{KC}$, Kim DH. Treatment strategy for frozen shoulder. Clin Orthop Surg 2019;11(3):249-57. [CrossRef]

2. Page P, Labbe A. Adhesive capsulitis: Use the evidence to integrate your interventions. North Am J Sports Phys Ther
2010;5(4):266.

3. Jankovic, D, Van Zundert A. The frozen shoulder syndrome. Acta Anasthesiol Belg 2006;57(2):137-43.

4. Clewley D, Flynn TW, Koppenhaver S. Trigger point dry needling as an adjunct treatment for a patient with adhesive capsulitis of the shoulder. J Orthop Sports Phys Ther 2014;44(2):92-101. [CrossRef]

5. Arias-Buría JL, Fernández-de-Las-Peñas C, Palacios-Ceña M, Koppenhaver SL, Salom-Moreno J. Exercises and dry needling for subacromial pain syndrome: A randomized parallel-group trial. J Pain 2017;18(1):11-8. [CrossRef] 